differences in the ionosphere overhead were unexpectedly found for stations only thirty miles apart. The biophysics group has studied the pathways and intermediate products in the synthesis of nucleic acid and protein constituents by supplying the nutrient medium with certain tracer-labelled compounds, selected as being specific compounds that may be formed in intermediate stages of the synthesis. The new procedures have been throwing light on the physical and chemical mechanisms by which the components of a protein are reproduced and on the degree of variability in precise constitution which is normal, for example, in the successive reproduction of a given protein. In particular, the method has been used for the study of the utilization of sulphate ions by Escherichia coli and the role of carbon dioxide in protein synthesis.

Further experimental work has been undertaken in the Department of Plant Biology to determine the conditions favouring the higher rates of growth of Chlorella with the view of the possible utilization of algæ for food and industrial raw materials. Arrangements have been made for A. D. Little, Inc., to set up and operate a Chlorella pilot plant, while further work in the Department has shown that the collection of Chlorella by continuous settling and re-use of the same growth medium for repeated batches of culture is practicable. Measurements of the fluorescence spectra of a red alga have provided evidence of the transfer of light energy absorbed by the accessory pigment phycoerythrin to chlorophyll and also to phycocyanin in the living alga. The time course of the development of the precursor of chlorophyll, protochlorophyll, has been followed in barley seedlings grown in the dark, and oxygen is not evolved in the photochemical transformation of protochlorophyll to chlorophyll. Extensive field investigations of the growth of grass hybrids have continued, including growth studies of $P o a$ hybrids and species under controlled conditions, their climatic tolerances and the genetics and evolution of Poa. The possibilities of using the results of experiments in controlled greenhouses to evaluate the productivity of specific grass strains in different natural climates has been further investigated. A preliminary study of the tertiary floras of Japan from Hokkaido to southern Honshu, with special reference to the distribution of Metasequoia and other members of the Arcto-Tertiary flora, has confirmed the hypothesis that changes in forest distribution during the past seventy million years have been of the same order and in the same direction in both Asia and North America.

The work of the Department of Embryology was interrupted by important changes of staff during the year; but although the output of published work was lower, progress was made in the investigations on the biochemistry and physiology of uterine muscle, on the transference of phosphorus across the placenta and in renal physiology. The rate of loss of the blood substitutes, dextran and polyvinylpyrrolidone, from the blood capillaries of organs of the dog was being investigated, and also the secretory activity of the ciliary body of the eye.

The Department of Genetics has been actively engaged in research pertaining to genes and the mechanical basis of heredity, and the report includes a full account of Dr. B. McClintock's work on mutable loci in maize, which has shown that at any one genelocus different alterations can occur, each initiating a particular kind of phenotypic expression of the initial instability. The methods developed in these studies will permit study of the mutation process by concentrating on the nuclear mechanisms that control when, where and how particular factors or genic components will be reactive in different cells and tissues of an organ. Continued studies of the mutagenic action of manganous chloride on Escherichia coli indicate that the action depends on the physiological state of the bacteria, which can be readily changed by varying the environmental conditions of treatment. In studies of the course of digestion of plant and animal cells, it has been demonstrated conclusively that trypsin in aqueous solution can degrade substrate materials of fixed cells. As the enzyme attacks specific linkages in the protein molecules, nucleic acids are released from their state of combination, and the cellular materials become capable of swelling like gels when- treated with inorganic salts and then water. This swelling in an intact cell rather than the dissociation of the protein molecules accounts for the disintegration. Methods developed in these studies have also shown that X-ray treatment of living larvæ of Drosophila alters the pattern of combination of nucleic acids and proteins in their salivary gland cells so that they swell less on treatment with trypsin, salts and water. Other X-ray studies have shown that the amount of crystalline trypsin inactivated varies with the solvent, the concentration of the enzyme and the $p \mathrm{H}$ of the solution, whereas with Escherichia coli the first direct genetic evidence has been obtained that the nucleus of the bacterial cell is actually a carrier of hereditary material. Observations on the production of heterozygous phage particles in crosses between mutants of the bacteriophage $T_{2}$ have indicated that genetic doubling is probably a constant feature of bacteriophage multiplication.

\section{FOREST POLICY IN UGANDA PROTECTORATE}

TN the 1949 forestry report for Uganda Protectorate (see Nature, 168, 507; 1951) it was stated that local governments were being encouraged to take over forestry work in areas where there were sufficient forests and that the district forest officer would act less and less in his official and trained capacity in these forests. It was pointed out that a similar action has been taken in other parts of the British Commonwealth-for example, in the Madras Presidency during the present century, when forests of the type in question were handed over to the care and management of the village Panchayats (communities). The result has been that a very large area of these forests has been destroyed by over, and wasteful, utilization; erosion has set in, with a reduction in water supplies; and the Forest Department has now been called in and has a difficult and uphill job in some areas. Yet thirty years ago these forests were under the efficient management of the Department.

In the forestry report for Uganda, covering the year ended December 1950*, the proposed devolution of the management of local forest areas is further developed. "This policy," says the report," "is resulting in the devolution of 'minor forestry' from the Protectorate Government. 'Minor forestry' may be defined as the management of the smaller reserves

* Uganda Protectorate. Annual Report of the Forest Department for the Year ended 31st December. 1950. Pp. iv +51. (Entebbe : Government Printer, 1951.) 38. 
of purely local significance ; the supervision of village forests ; the creation of plantations of fast-growing trees for supplies of building poles and firewood necessary for the economy of rural areas and minor townships ... etc." Also, the local government should take over the management of all natural tree growth on Crown lands. The report continues: "Although it is a prior condition that the local government shall have the will and competency to undertake the additional duties attendant on devolution, it is a disagreeable fact that no local government has as yet the competency. The management of local forestry is still very largely the concern of the District Forest Officers, and local staffs are for the most part painfully inadequate. Few local governments are able to pay wages comparable with those given by the Protectorate; and even if suitable men are produced for training, they are young men who lack experience and consequently lack authority with chiefs and the people. In many districts the only alternative appears to be to second Protectorate Rangers". The management of the classes of forest herein contemplated, which are of primary importance to the local communities, is very far from being the easy or simple job which the Civil departments of the British Administration have so often regarded it in the past. The trained forest officer's job was, and is, considered to be in the big forests from which timber and revenue comeotherwise the Department is not paying its way.

In some parts of the world, by no means confined to the British Commonwealth, there are large populations living in hot countries where over great tracts of land the forest is represented by a scrub of varying height, growth, consistency and species, with grass for grazing, and so forth, the maintenance of which is essential to the well-being of the local populations and to their agricultural occupations. The continuance and, if possible, improvement of this type of forest, for forest it is, are as vital in the administration of the country as are the big timber forests, and demand often the highest skill of the trained and experienced forest officer-the district forest officer alluded to in the Uganda report. Such knowledge is not possessed by the Civil authority, nor by village communities, and to apply it requires a greater authority than that of a Protectorate ranger.

E. P. Stebing

\section{THE OPENING OF MILK BOTTLES BY BIRDS}

$\mathrm{T}$ $\mathrm{HE}$ opening of milk bottles by birds is now a well-known habit throughout most of the British Isles and has previously been described in Nature $(165,435 ; 1950)$. Further information has now been collected by R. A. Hinde and James Fisher, and includes records from the British Isles and other countries (British Birds, 44, No. 12; 1952).

In Sweden, as in Britain, observations have been made of the opening of milk bottles by blue tits and great tits. The habit is said to be widespread and that "magpies and blackbirds" also raided the bottles. In Vendolso tits have been observed opening coffee cream bottles. In Denmark the habit is also well known, and, in suburban districts, is said to be almost a nuisance; the main birds are the great tit and the great spotted woodpecker (Dendrocopus major). In Copenhagen the opening of bottles by great spotted woodpeckers is reported to be a general practice. Along the south border of the Geel forest jackdaws have been seen opening bottles.

Inquiries made by Dr. L. Tinbergen in Holland indicate that bottle opening occurs in at least twenty-one localities south of the Zuider Zee ; in all cases where the bird was certainly identified it was a great tit. Milk bottles practically disappeared from Holland during the War and only became reasonably common again in 1947-48. It is unlikely that many tits which had learnt the habit in pre-war years still survived at this date, so the habit must have originated in all the recorded localities since 1948. Since great tits are relatively sedentary birds, it seems certain that the habit was started in many different places and by many individuals.

In the United States a photograph of a Steller's jay (Cyanocitta stelleri) opening a milk bottle has appeared in a Seattle newspaper.

Although no experimental analysis of the behaviour involved in the opening of milk bottles has yet been made, further observations in the field enable the discussion to be carried further. Previously the processes were considered in two parts - the 'recognition' of the milk bottle as a potential supply of food and the technique of opening the bottle. The actual opening of the bottle probably depends on innate motor patterns, and the study of tits in the field has confirmed this view. The movements used are the same as those used when feeding on natural foods. For example, the hammering action with which foil caps are punctured is very similar to a motor pattern used in opening nuts, and the tearing action often used on cardboard tops is similar to a movement used in tearing bark from a twig.

It has been suggested that the initial 'discovery' of the bottle as a source of food may be a logical consequence of the feeding habits of tits. They appear to have an inborn tendency to inspect a great variety of conspicuous objects which contrast with their surroundings, and to test their palatability. If the outside of the object is unpalatable, they may attempt to open it by hammering - hammering seems to be evoked by the sound of a hollow object. In fact, it seems that, when tits are looking for food, objects with certain very general characteristics may be sufficient to release a more limited type of searching behaviour (such as flying to the food). By a succession of similar steps (hammering, etc.), evoked by successively more specific stimuli, a reward may eventually be obtained. It so happens that milk bottles have sufficient characteristics in common with the natural foods for tits occasionally to 'discover' them in the course of their normal searching.

When a bird has fed once or a few times at milk bottles, it will learn to return to them on later occasions, presumably by a form of trial-and-error learning. On these subsequent occasions the bird may come to respond to quite different stimuli from those which controlled its behaviour the first time. For example, if milk bottles with differently coloured stoppers are available, the tits will often concentrate their attacks on those having stoppers of one particular colour - presumably because the colour of the top was one of the characters which the bird learnt on the first visits.

Hinde and Fisher also suggest that the apparent copying of the behaviour by other individuals is probably due to another process-local enhancement - which modifies the appetitive behaviour of feeding and is initially independent of reward. 